\title{
A Proximate Mirror: Greenhouse Gas Rules and Strategic Behavior Under the US Clean Air Act
}

\author{
Dallas Burtraw ${ }^{1} \cdot$ Karen Palmer $^{1} \cdot$ Anthony Paul $^{1}$. \\ Sophie Pan ${ }^{1}$
}

\begin{abstract}
The development of climate policy in the United States mirrors international developments, with efforts to initiate a coordinated approach giving way to jurisdictions separately taking actions. The centerpiece of US policy is regulation in the electricity sector that identifies a carbon emissions rate standard (intensity standard) for each state but leaves to states the design of policies, including potentially the use of technology policies, emissions rate averaging, or cap and trade. Differences in policies among states within the same power market could promote predatory behavior resulting in a geographic shift in generation and investment in new resources. This paper examines the coordination problem using a detailed partial equilibrium model of operations and investment. We demonstrate that leading jurisdictions have available a rich set of design options including targetted output based allocation that would impose costs on neighbors and may protect against strategic predation.
\end{abstract}

Keywords Climate policy · Efficiency · Equity · Clean Air Act · Coal · Compliance flexibility $\cdot$ Regulation $\cdot$ States

JEL Classification $\quad \mathrm{K} 32 \cdot \mathrm{Q} 54 \cdot \mathrm{Q} 58$

Dallas Burtraw

Burtraw@RFF.org

Karen Palmer

Palmer@RFF.org

Anthony Paul

Paul@RFF.org

Sophie Pan

Pan@RFF.org

1 Resources for the Future, 1616 P Street NW, Washington, DC 20036, USA 


\section{Introduction}

The development of climate policy in the United States mirrors international developments, with efforts to initiate a coordinated approach giving way to regimes in which jurisdictions are separately taking actions with differing policy designs. Independent policy design introduces opportunities for strategic behavior that can lead to leakage of economic activity and emissions and increase overall costs or emissions or both. Jurisdictions that exercise policy leadership in the stringency or design of their policy may be especially vulnerable to strategic interaction. Their costs may rise because of the policy choice of neighboring jurisdictions, which in turn may benefit from predatory behavior, undermining the prospect for climate policy. Using the US electricity sector as an example, we exercise a detailed simulation model to demonstrate that leading jurisdictions have available a rich set of design options that can protect them against strategic predation and in fact give them opportunities to proactively advance climate goals.

US climate policy is taking shape through the Climate Action Plan, announced by President Obama in June 2013. The plan encompasses improved motor vehicle standards, additional appliance efficiency standards, and regulation of greenhouse gases from a variety of sources. It includes an inflexible carbon dioxide $\left(\mathrm{CO}_{2}\right)$ emissions rate standard for new fossil-fired facilities comparable to that of a new natural gas combined-cycle unit. This standard effectively requires the application of carbon capture and storage at new coal-fired facilities; however, few new coal-fired facilities are likely to be built in the near term. The centerpiece, the Clean Power Plan (CPP), is directed at existing sources in the electricity sector, which are responsible for about $38 \%$ of total national $\mathrm{CO}_{2}$ emissions. The $\mathrm{CPP}$ introduces regulations under the federal Clean Air Act aimed at reducing emissions in the electricity sector by $32 \%$ from 2005 levels by 2030.

The CPP embodies the familiar framework of cooperative federalism in US environmental law. It establishes a carbon emissions rate standard of performance (intensity standard) for each state, but leaves to states the responsibility for planning, implementation, and enforcement to achieve the standard. The standard is founded on technology-based building blocks that identify options in each state and adopts a system-based approach including investments in nonemitting resources to implement emissions reductions across the electricity sector. States are granted remarkable flexibility, including the possibility of using technology policies or economic incentives such as emissions rate trading (averaging), cap and trade, or taxes to achieve the performance standard. States may develop multistate plans to average emissions rates across states, or adopt regional cap-and-trade approaches. The US Environmental Protection Agency (EPA) issued its final rule in August 2015 giving states a timetable to prepare a plan for compliance or face the imposition of a federal plan. Initial compliance is expected in 2022 with credit given for measures adopted before then.

The recent change of course in US climate policy is abrupt. In 2009 the US House of Representatives passed comprehensive national climate legislation that would have introduced economy-wide cap and trade as a centerpiece. The legislation did not come to a vote in the Senate and its demise in 2010 cast a shadow on the prospects for climate policy in the United States. Three years later, policy of similar stringency began taking shape. In the electricity sector, the centerpiece is a bottom-up process in which state jurisdictions make separate choices about how they will comply.

The change in course within the United States somewhat parallels changes that have occurred in international climate negotiations. The Conference of the Parties to the international negotiations met in Berlin in 1995 to launch the process that eventually led to the 
Kyoto Protocol in 1997 and introduced an ambitious obligation on signatories. The refusal of the United States to ratify the treaty and the disaffection of other parties undermined that coordinated approach. Strategic and competitive interactions have since influenced the international debate. If one were to imagine the Kyoto Protocol as a cooperative solution to a strategic problem, it shared a characteristic inherent to cooperative game theory in general: the solution did not specify incentive-compatible steps to achieving the outcome.

Internationally, the current potential for optimism resides in the prospects for a bottomup process of nationally determined contributions. This pledge and review process among nations more closely resembles a noncooperative solution. The theoretical question with relevance internationally and in the United States is whether this type of bottom-up approach can solve the difficult coordination challenge to achieve an outcome that is effective.

One step to solving the challenge to date appears to involve the proliferation of technology policies, which are often described as enabling or complementary to the emergence of comprehensive approaches. For example, in the European Union, renewable policies have contributed to low prices in the emissions trading system, encouraging the adoption of more stringent emissions targets (Koch et al. 2014). In the United States, the stringency of the CPP is based on findings about the technical feasibility of reducing carbon emissions, drawing on the variety of technology policies already in place in the states. ${ }^{1}$ The economics literature has broadly characterized these policies as a potentially inefficient way to achieve emissions reductions (Böhringer and Rosendahl 2010; Fischer et al. 2013). However, we suspect that if a bottom-up climate policy is going to succeed, perhaps eventually leading to a coordinated and comprehensive solution, it is likely to require the learning and coalition building that are achieved through such an incremental process (Keohane and Victor 2013).

In the United States, the coordination challenge is perhaps simplified because EPA has determined the stringency of state goals, while there is nothing comparable internationally. However, the nearly absolute flexibility in policy design under the CPP provides states with a monumental coordination challenge as complex as that at the international level. Emerging as a central question for states is the form and reach of their plans. Form pertains to the policies that will be enacted in each state, such as technology standards, incentives for renewables and energy efficiency, and cap and trade. Reach pertains to the interaction of each state with its neighbors. ${ }^{2}$ Multistate coordination would allow states to capture the efficiency of harmonizing policies across diverse situations. Even more important, however, is the overlap between compliance activities at the state level and the power planning regions and markets that cover multiple states and sometimes divide states. As we describe below, the policy designs chosen by states may interact with power markets to cause geographic shifts in electricity generation and investment in new facilities, raising costs, emissions, or both. A state might respond to decisions of its neighbors to its own benefit and at their expense. Even if states choose the same design, the variation in stringency among states that is inherited from EPA could lead to negative outcomes.

This paper examines the coordination problem in the context of the US electricity sector using a detailed partial equilibrium model of operations and investment through 2035 to

1 For example, over 30 states have renewable portfolio standards (NCSU 2013) and 25 have meaningfully funded long-term (3+years) energy savings targets or energy efficiency resource standards (ACEEE 2014). In California, which has economy-wide cap and trade in place, approximately $83 \%$ of the emissions reductions necessary to achieve the state's climate goals for 2020 will be achieved by regulatory standards and measures.

2 Multi-state discussions to develop regional compliance stgrategies have already begun in several regions of the country. A consensus on the policy design has so far emerged only the northeast region, where there is a pre-existing cap-and-trade program encompassing nine states, and that is the region's preferred approach for compliance with the CPP. 
examine interactions among state policies and power markets. We focus on policy options in one region, the upper Midwest, holding stable the policy choice of an emissions rate standard in the rest of the nation. This region is of interest because it comprises states with both cost-ofservice regulation and competitive market structures, and it has a variety of resource options.

We compare an emissions rate standard with emissions cap and trade in the upper Midwest while holding the rest of the nation constant with an emissions rate standard. Under some forms of cap and trade in the upper Midwest, the interaction with the rest of the nation can provide substantial cost advantages to the rest of the nation under its emissions rate standard, causing operations and investment to shift away from the cap and trade region. Because the emissions rate standard does not place a cap on total emissions, this policy combination can increase emissions overall compared with the outcome if both regions have an emissions rate standard. However, some options for allowance allocation under cap and trade can impact the interaction and lead to zero change in total emissions. We show that if states use an output-based allocation they can mimic the production incentives created under the emissions rate standard. Recognizing that this equivalence is possible, one can imagine targeted output-based allocation that could favor low-emitting or non-emitting technologies and achieve negative leakage, with operations and investment flowing into the region with an emissions cap and lowering total emissions, which we demonstrate in the model.

The ability of states to use targeted output-based allocation to preserve the level of operations and investment that would occur if they used the emissions rate standard means that states can consider the use of cap and trade to harvest its many administrative advantages over an emissions rate standard without suffering economic penalty. Costs under these outcomes vary under different policy combinations, but in some cases are less in the cap and trade region and greater under emissions rates in the rest of the nation. In effect, this outcome demonstrates a strategic response by the cap and trade jurisdiction to a defection strategy (the choice of an emissions rate policy) by its neighbors. These findings are consistent with the expectation (not shown here) that the lowest costs overall would be achieved under a coordinated approach.

In the next section of this paper we describe the US policy context in more detail and review the international literature on the interaction between emissions rate (intensity) standards and cap and trade. In Sect. 3 we introduce the model and describe the scenarios that reflect state policy options. In Sect. 4 we describe results, including the possibility for perverse outcomes and strategic predatory behavior, and defensive responses to prevent this outcome. Section 5 provides a concluding discussion.

\section{Policy Background and Literature}

EPA presented a final version of the CPP in August 2015. The rule establishes an adjusted emissions rate performance standard for each state based on the availability of coal-fired and natural gas-fired facilities and the potential for new gas facilities and renewable energy. Under rate-based compliance programmatic investments in energy efficiency are given credit. States also have the option of using a mass-based emissions budget (cap), which would simplify many aspects of implementation, including evaluation of energy efficiency programs and interstate collaboration. ${ }^{3}$ States may also identify a combination of other policy measures

3 Fowlie et al. (2014). 
that would achieve the emissions budget. The stringency of the targets can vary significantly among states because of variation in their resources. ${ }^{4}$

The Climate Action Plan and the CPP encourage flexible implementation including emissions rate averaging or trading, and cap and trade. ${ }^{5}$ The cost savings from a flexible approach could be substantial, especially if implemented on a regional or national basis. Burtraw et al. (2012) and Linn et al. (2014) show that a national standard for reducing $\mathrm{CO}_{2}$ emissions from the electricity sector can cost 70-90\% less than a traditional (nontradable) performance standard.

\subsection{Potential Policy Interactions}

The focus of this paper is how measures in one state will interact with those of other states. For example, double-counting might occur if one state provided incentives for renewable projects that were built in another state. Another issue is how to give credit for energy efficiency investments that reduce demand in one state but, due to interstate electricity transmission, reduce emissions in another. These and other issues are largely resolved if states join in regional compliance efforts under a cap-and-trade system.

Another way that state policies will interact is through the movement of power and new investment in the electricity market, which may present an obstacle to regional compliance efforts. Besides introducing a price on emissions, an emissions rate standard also provides an incentive for production because the firm earns emissions credits per unit of production (Fischer 2003). If the facility's emissions rate is less than the standard, the facility has a net credit from the difference between its observed performance and the standard. If two states have different emissions rate standards, incentives may exist to shift generation and investment to the jurisdiction with a less stringent standard. The shift may lead to the utilization of different fuels and technologies, ultimately increasing emissions of $\mathrm{CO}_{2}$ as well as changing the location and magnitude of other pollutants, including sulfur dioxide $\left(\mathrm{SO}_{2}\right)$ and nitrogen oxides $\left(\mathrm{NO}_{x}\right)$.

Differences in production incentives would be even greater if one state chooses to use conventional cap and trade without a production incentive and a neighboring jurisdiction retains its emissions rate standard. In effect, the production incentive in the capped region is zero; for example, if emissions allowances are distributed through an auction, then facilities must purchase all of their allowances. Even if a cap-and-trade program distributes emissions allowances for free, as was the practice under the Title IV Acid Rain Program for $\mathrm{SO}_{2}$ emissions and in the early phases of the European Union's Emissions Trading System, there typically does not exist a production incentive because the volume of allowances distributed to facilities does not depend on its economic activity. In this case, capping emissions in one jurisdiction creates incentives for a shift in production and investment to neighboring jurisdictions that do not cap emissions (Marschinski 2008; Burtraw et al. 2014).

\subsection{Production Incentives Under Various Policy Designs}

The policy strategy we investigate is the incorporation of a production incentive in the design of a cap-and-trade program through the allocation of emissions allowances on the basis of

\footnotetext{
4 An important issue that states must resolve in their plans is how new emitting sources should be treated.

5 In a memorandum to EPA in June 2013, President Obama articulated the political directive to "ensure, to the greatest extent possible, that [EPA]...develop approaches that allow the use of market-based instruments, performance standards, and other regulatory flexibilities; [and] ensure that the standards enable continued reliance on a range of energy sources and technologies." See http://www.whitehouse.gov/the-press-office/2013/06/ 25/presidential-memorandum-power-sector-carbon-pollution-standards (accessed December 20, 2014).
} 
economic activity (electricity generation). First, we evaluate a scenario in which all states use a tradable emissions rate policy to comply with the emissions rate target assigned to states under the CPP. In other scenarios we hold this emissions rate policy constant for most of the nation, but vary the policy in one region — the upper Midwest—where we consider various formulations of a cap-and-trade policy.

We find the possibility for generation and emissions changes depend on the form of the cap-and-trade program. In one case, we imagine the emissions allowances in the cap-andtrade policy are auctioned, with revenues leaving the electricity sector (equivalent to an emissions tax or lump-sum climate dividend). The removal of the production incentive in the upper Midwest region results in leakage of generation and emissions to other regions and an increase in overall emissions. In another case, we imagine the revenues remain in the electricity sector as a consumption incentive to consumers through their local distribution company, as proposed in 2009 in the Waxman-Markey proposal for national-level cap and trade, and again we find substantial leakage and an increase in emissions. In other cases, we imagine targeted production incentives (updated output-based allocation) that reward utilization of specific technologies, and we show in these cases leakage can be stopped or reversed, with a decrease in total emissions compared with tradable emissions rate policies in all states. Because the cap-and-trade program offers other administrative advantages, this outcome is encouraging.

In general, the production incentive leads to more production from the targeted technologies, but it is informative to consider an example where that might not happen. If there were only one type of technology and a binding emissions cap were in place, the only way to achieve emissions reductions would be through a proportional reduction in generation from these facilities. The production incentive would drive up allowance prices, with no change in the generation mix (Bushnell and Chen 2012). In a dynamic model with an opportunity for investment, decisionmakers also anticipate the consequences of generation or emissions with respect to their allocation in a subsequent period, driving up short-run allowance prices (Harstad and Eskeland 2010). ${ }^{6}$ Hence, the price of emissions allowances is not a good measure of the marginal cost of emissions reductions when there is a production incentive because it is actually the marginal cost conditional on the subsidy.

One way that output based allocation can be effective is by directing the production incentive to achieve greater use of and investment in low- or non-emitting resources within the regulated region (Fischer 2003; Burtraw et al. 2006). Such an approach is evident in the Northeast's Regional Greenhouse Gas Initiative cap-and-trade program, where approximately two-thirds of the value of emissions allowances is directed to investments in energy efficiency, which can be thought of as a non-emitting resource (Burtraw and Sekar 2014). However, the distribution of costs among consumers, incumbent generators, and new investors typically varies. Consumers may prefer to coordinate around a tradable performance standard that provides incentives for production because it affects on the variable cost of the marginal electricity generator and thereby affects prices, while producers may prefer to coordinate around cap and trade with revenues used to provide incentives for consumption (Burtraw et al. 2006) or not to coordinate (Bushnell et al. 2014). Holland (2012) shows that outputbased allocation can dominate a tradable performance standard (in its economic efficiency) if it can mimic the optimal combined emissions price and output subsidy. The potential superiority of output-based allocation, Holland notes, can be attributed to its flexibility. We

6 Rosendahl and Storreøsten (2011) show that if allowances were based on the updated share of emissions, investment and retirement would be equivalent to grandfathered allocation, but the result hinges on the assumption of no banking of emissions allowances across periods. 
note that the CPP allows states such flexibility. Although economic costs vary under different policy combinations, they are expected to be lowest under a coordinated approach (Holland 2012), if that approach can be sustained.

\section{Model and Scenario Descriptions}

We use a highly parameterized electricity market simulation model to characterize the response of the electricity system to a variety of potential climate policies undertaken by states and examine the regional interactions of those policies.

\subsection{The Haiku Electricity Market Model}

The Haiku electricity market model $^{7}$ is a partial equilibrium model that solves for

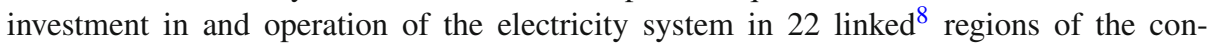
tinental United States, from 2013 to 2035. Each simulation year is represented by three seasons (spring and fall are combined) and four times of day. For each time block, demand is modeled for three customer classes (residential, industrial, and commercial) in a partial adjustment framework that captures the dynamics of the long-run demand responses to short-run price changes. Supply is represented using 53 model plants in each region, including various types of renewables, nuclear, natural gas, and coal-fired power plants.

Operation of the electricity system (generator dispatch) in the model is based on the minimization of short-run variable costs of generation, and a reserve margin is enforced based on margins used by the Energy Information Administration in the Annual Energy Outlook (AEO) for 2013 (EIA 2013). Investment in new generation capacity and the retirement of existing facilities are determined endogenously ${ }^{9}$ for an intertemporally consistent (forwardlooking) equilibrium, based on the capacity-related costs of providing service in the present and into the future (going-forward costs) and the discounted value of going-forward revenue streams. Price formation is determined by cost-of-service regulation or by competition in different regions, corresponding to current regulatory practice. Additional background on the model is provided in an "Appendix".

\subsection{Modeling Scenarios}

We use this policy laboratory to analyze and compare a tradable emissions rate performance standard program and various forms of cap and trade in the electricity sector, and we examine the policy interaction across regions under various settings.

\footnotetext{
7 Haiku is comparable in sectoral and geographic coverage to the Integrated Planning Model (IPM, owned by ICF consulting and the model of record for EPA), ReEDS (maintained at the National Renewable Energy Laboratory), and the Electricity Market Module of the National Energy Modeling System (NEMS, maintained by the Energy Information Agency). Haiku, IPM, and ReEDS model the electricity sector and partially model factor markets, like fuel, for the continental United States. NEMS also links its electricity sector model to the entire economy and models all fuel markets. For more information about the Haiku electricity market model, see Paul et al. (2009).

8 Interregional transmission capability is drawn from EIA (2013).

9 Investment (in both generation capacity and pollution controls) and retirement are determined according to cost-minimization.
} 


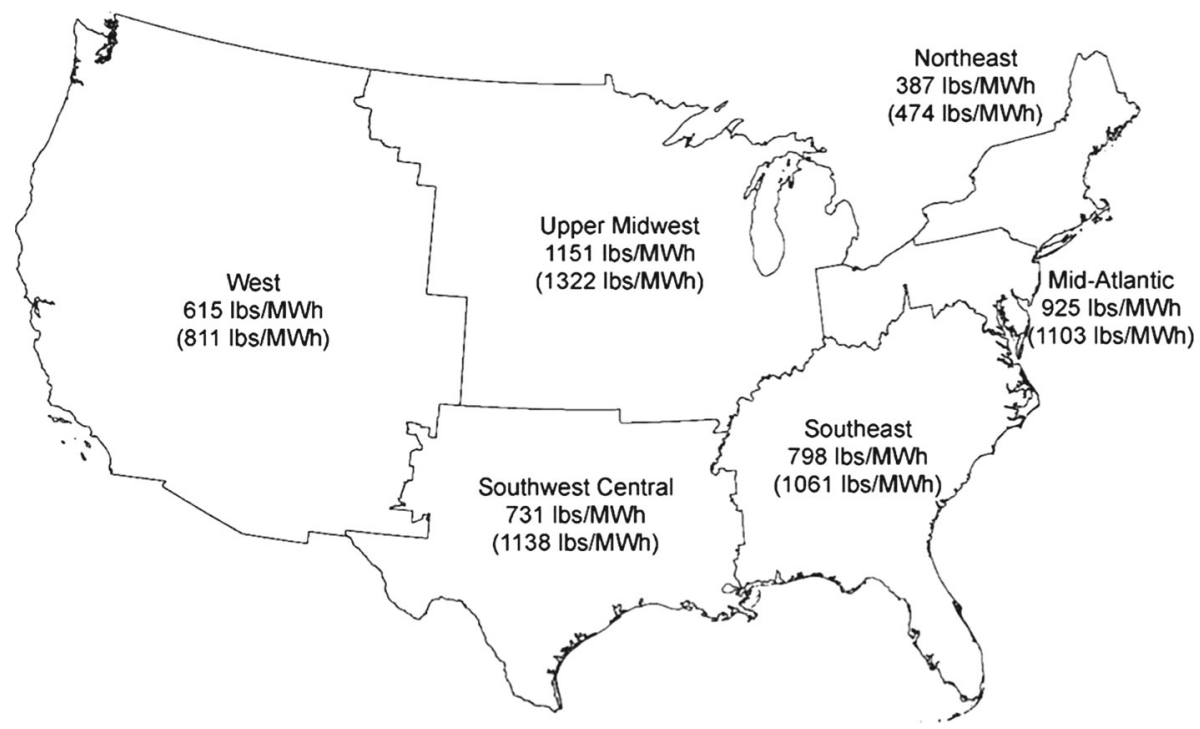

Fig. 1 Regional configurations with 2020 emissions rate targets (with baseline emissions rates)

\subsubsection{Baseline Scenario}

The Baseline includes all of the major environmental policies affecting the electricity sector. This includes the $\mathrm{SO}_{2}$ trading program under Title IV of the Clean Air Act, the Regional Greenhouse Gas Initiative, the federal renewable energy production and investment tax credit programs, California's cap-and-trade program, and all of the state renewable peformance standards and renewable tax credit programs. ${ }^{10}$ The Baseline also includes the Mercury and Air Toxics Standards, which have been finalized by EPA and fully take effect in 2016 in our model, and state-level mercury standards. Finally, the Baseline includes the Clean Air Interstate Rule in place of the Cross-State Air Pollution Rule, which was struck down by the court and recently reinstated but is not yet in effect. This can be taken to represent a future regulation on $\mathrm{SO}_{2}$ and $\mathrm{NO}_{x} \cdot{ }^{11}$ The Baseline is calibrated to the AEO (EIA 2013). All of the characteristics of the Baseline are held constant in the policy scenarios except for the Regional Greenhouse Gas Initiative and California's cap-and-trade program, which for simplicity are not maintained in these experiments, and otherwise as discussed below.

\subsubsection{Policy Scenarios}

We model six compliance regions, of which only one region (upper Midwest) has varying policy formulations across scenarios; the other five regions keep the same policy, a rate-based tradable performance standard. The regions and emissions rate standards are shown in Fig. 1.

\footnotetext{
10 We assume the production tax credits expire by 2017 but some investments receive credits over a duration of 10 years.

11 Our previous modeling has shown only small changes to the electricity sector if the Clean Air Interstate Rule is replaced with Cross-State Air Pollution Rule when the Mercury and Air Toxics Standards are also in effect. Thus the choice between modeling these two $\mathrm{SO}_{2}$ and $\mathrm{NO}_{x}$ regulations is of little significance in this analysis.
} 
The various annual emissions rate standards do not vary under alternative scenarios, but emissions can vary. In contrast, we calibrated the upper Midwest to achieve a $\mathrm{CO}_{2}$ emissions trajectory in every scenario for each year through 2035 that matches the emissions outcome under the tradable performance standard. These emissions rates and emissions targets are based on a careful representation of the CPP in Haiku as proposed by EPA in June $2014^{12}$ and result in emissions reductions close to EPA's estimate for the CPP. This regional policy configuration facilitates the study of emissions leakage.

Besides the regional differences, the policy treatments in all the scenarios have shared features across regions. The population of generators covered by regulation is the same: all fossil-fired generators, ${ }^{13}$ all renewables (except existing hydro), and new and at-risk ${ }^{14}$ nuclear generators. ${ }^{15}$ The treatment of energy efficiency (EE) programs in compliance is also the same and is constant across all scenarios at a level of funding determined by a system benefit charge of $\$ 3 / \mathrm{MWh}$, and effectiveness is described by end-use demand reduction at a first-year program cost of $\$ 180 / \mathrm{MWh} .{ }^{16}$ We assume an equal participant cost for EE investment is paid by the consumer and include that cost in our economic surplus estimates.

In policy experiments, we compare several approaches in the upper Midwest that differ in the form of the policy and allocation of allowance revenue. The first is a rate-based tradable performance standard (TPS). The others have a mass basis, with differences in the allocation of the asset value created by introducing a price on carbon: allocation to government, to consumers, and to producers. These policies correspond to a revenue-raising auction (government), an emissions budget with allocation to local distribution companies (LDCs), and an emissions budget with targeted updated output-based allocation (OBA) with several variants.

Tradable Emissions Rate Performance Standard A tradable emissions rate performance standard sets an emissions rate that the regulated sources must meet on average. This could be achieved through a regulatory process or planning process within a firm, but we imagine a market analogue in which generators are obligated to surrender credits equal to their actual emissions rate multiplied by their annual generation and are entitled to earn credits equal to the benchmark emissions rate multiplied by their annual generation. The net compliance obligation stems from the difference between the benchmark and actual emissions rates. In this scenario, we implement tradable performance standards in six regions. In the following scenarios, we implement tradable performance standards in five regions; only the upper

\footnotetext{
12 We simulated six tradable performance programs in six compliance regions with emissions rate targets that are the blended (generation weighted average) emissions rate goals for each state in the region established in the proposed CPP for the compliance period 2020-2035. The proposal allows for moderate interannual flexibility between 2020 and 2029, followed by annual compliance through 2035. We solve the model to find a least-cost emissions rate pathway over this period and then implement the identified regional emissions rate targets on an annual basis in the scenarios we model. We use the observed emissions in each year to determine the emissions budget in the upper Midwest over the compliance period.

13 The CPP is ambiguous with respect to inclusion of new fossil sources.

14 The CPP views an approximately $5.8 \%$ share of nuclear capacity as a reasonable proxy for the amount of nuclear capacity at risk of retirement (Clean Power Plan Proposed Rule: GHG Abatement Measures, Technical support document, U.S. EPA, 2014).

15 The covered sources are the denominator in the CPP's formula for state goal plus new natural gas combinedcycle.

16 All values are in 2011 dollars. Factoring EE programs in assessing compliance was suggested by EPA in the proposed rule. The modeling of EE programs affects electricity prices and generation investment endogenously in a dynamic timeframe. Energy savings persist and decay over time based on the partial-adjustment structure of the Haiku demand system. EE expenditures are allocated to consumer classes based on consumption shares.
} 
Midwest varies the policy design, and in doing so states in the Midwest region use the asset value created by the emissions constraint in various other ways.

Emissions Budget with Auction Revenues to Government The remaining scenarios involve the translation of the emissions rate standard to a mass-based emissions budget for the upper Midwest. The emissions outcome in the region in the remaining scenarios is the same as under the tradable emissions rate performance standard.

One approach is to characterize the program as an emissions cap-and-trade program with allowances auctioned and revenues from the auction accruing to the government, equivalent to an emissions tax with the level of the tax calibrated to achieve the emissions budget. In this scenario, the allowance asset value leaves the electricity sector.

Emissions Budget with Allocation to Local Distribution Companies In this scenario, cap and trade is implemented in the upper Midwest and the allowance asset value stays in the electricity sector; it is allocated to LDCs in proportion to their share of consumption. As regulated entities, LDCs are assumed to direct the value to the benefit of consumers. This could be achieved in a variety of ways; the assumption in this scenario is that the value is applied as a credit on customers' electricity bills. Consequently, consumers are expected to pay lower retail electricity prices in this scenario than in the Government scenario and react to lower prices by increasing consumption.

Emissions Budget with Targeted Updated Output-Based Allocation We investigate several forms of cap and trade in the upper Midwest with allowance value allocated to different sets of eligible electricity producers based on their share of electricity generation within the set. Because shares of generation change over time, this approach is labeled updated outputbased allocation. It is modeled as a contemporaneous equilibrium; in practice this approach is implemented by looking back to a recent period when data are complete. We describe this as targeted allocation because the allowance revenue is concentrated to a subset of all resources. We describe four approaches in Table 1.

The policy scenario labeled TPS (OBA-All Covered) allocates the allowance value to the set of covered (regulated) generators on the basis of their share of production by these generators. Hence, this approach is conceptually identical to a tradable performance standard covering the same set of generators, and the modeling of these two policies is identical if the emissions outcomes are constrained to be equal.

The OBA-All scenario allocates the allowance value to all generators including existing nuclear and hydro. These resources are nonresponsive to a production incentive since they produce at their maximum availability in the Baseline. Consequently, their eligibility for an allocation reduces the production incentive that is available to other technologies that can respond to the production incentive.

In the scenario OBA-ExCoal, allocation occurs to covered generators except coal. This would appear to focus the production incentive more directly on lower-emitting resources. However, in equilibrium, because coal does not receive the incentive, there is likely to be less coal generation, and the scarcity value of emissions credits or allowances will be reduced. These factors have somewhat offsetting effects on the production incentive that is delivered to the eligible sources.

Finally, under the scenario OBA-New NonEm, only new renewables, new nuclear, and at-risk nuclear are eligible to receive allocation.

The introduction of production incentives influences the variable cost of electricity generation, and the variation under the policy options can promote the use of one technology 
Table 1 Policy scenarios using targeted updated output-based allocation

\begin{tabular}{|c|c|c|c|c|c|c|}
\hline \multirow{2}{*}{$\begin{array}{l}\text { Generator } \\
\text { type }\end{array}$} & \multicolumn{6}{|c|}{ Production eligible for allowance allocation } \\
\hline & $\begin{array}{l}\text { Covered } \\
\text { sources }\end{array}$ & $\begin{array}{l}\text { TPS (OBA-All } \\
\text { Covered) }\end{array}$ & Government & OBA-All & OBA-ExCoal & $\begin{array}{l}\text { OBA-New } \\
\text { NonEm }\end{array}$ \\
\hline \multicolumn{7}{|l|}{ Fossil } \\
\hline Coal & $\mathrm{X}$ & $\mathrm{X}$ & & $\mathrm{X}$ & & \\
\hline Natural gas & $X$ & $X$ & & $X$ & $X$ & \\
\hline Oil & $X$ & $X$ & & $X$ & $X$ & \\
\hline \multicolumn{7}{|l|}{ Renewables } \\
\hline Existing & $X$ & $X$ & & $X$ & $X$ & \\
\hline New & $\mathrm{X}$ & $\mathrm{X}$ & & $\mathrm{X}$ & $\mathrm{X}$ & $\mathrm{X}$ \\
\hline \multicolumn{7}{|l|}{ Nuclear } \\
\hline Existing & & & & $\mathrm{X}$ & & \\
\hline New, at-risk & $X$ & $X$ & & $\mathrm{X}$ & $X$ & $X$ \\
\hline Hydro & & & & $X$ & & \\
\hline Efficiency & $\mathrm{X}$ & & & & & \\
\hline
\end{tabular}

$O B A$ output-based allocation, TPS tradable performance standard

at the expense of another. If the favored technology is new investment, the incentives could lead to greater investment. Nonetheless, existing sources may continue to be available even if they do not receive the production incentive.

Figure 2 displays the forecast merit cost ordering for electricity generation for a portion of the supply curve. Generation is organized into six generation types for the upper Midwest during the baseload summer block in 2020 under two policy scenarios. ${ }^{17}$ The solid symbols represent the variable costs under the Government scenario, organized according to merit order. The available production capacity in this scenario is measured on the horizontal axis. The second set of costs displayed on the figure reflects the variable costs under output-based allocation to all covered sources excluding coal (OBA-ExCoal), without any reordering of the plants according to the new variable cost schedule. The variable cost of each plant is affected by the change in the carbon price and in many cases by the availability of a production incentive.

Three observations are evident. One is that the variable costs under OBA-ExCoal are generally lower than under the Government scenario, as would be expected because of the production subsidy, which is likely to result in more generation from within the region than under the Government scenario, helping to reduce leakage. Second, the difference in variable costs depends on technology. As evident in the next section, coal generation is advantaged under OBA-ExCoal because the allowance price that emerges in equilibrium is less than under the Government scenario, renewables are advantaged because they receive the production incentive, and natural gas benefits for both these reasons. Third, the variable costs under OBAExCoal are not monotonically increasing under the ordering of technologies that is presented. A reordering of the technologies will favor greater utilization of some technologies and a change in capacity.

Figure 3 portrays the new merit order under OBA-ExCoal compared with the merit order under the Government scenario after the plants have been reordered. Changes in plant retire-

17 Individual generating units are aggregated as model plants, as in the Haiku model. 


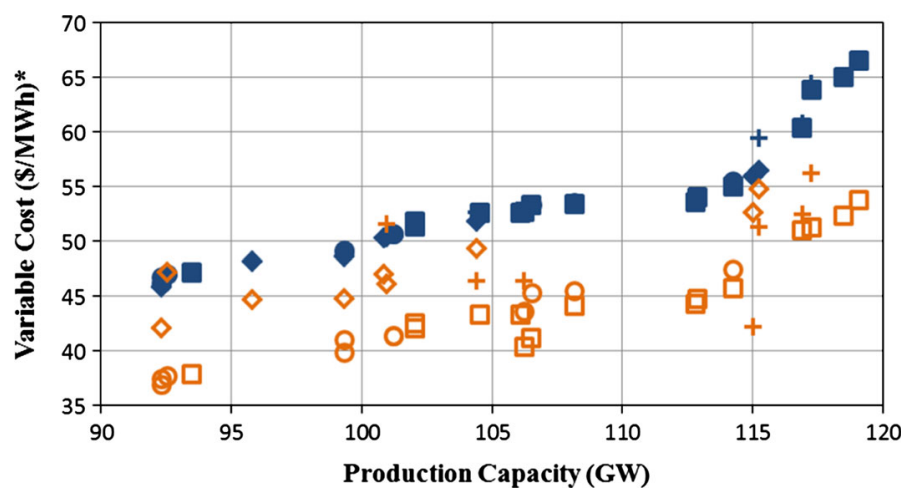

\begin{tabular}{|c|c|c|c|c|c|}
\hline Scenarios: & Government & 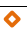 & OBA-Excluding Co & & \\
\hline \multirow[t]{2}{*}{ Technologies: } & Coal & $\square$ & Existing Gas \& Oil & स & Existing RE \\
\hline & Nuclear & 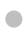 & New Nat Gas & + & New RE \\
\hline
\end{tabular}

Fig. 2 The variable cost schedule under cap and trade when revenues are distributed to government and the same plant ordering with targeted output-based allocation excluding coal (upper Midwest, 2020)

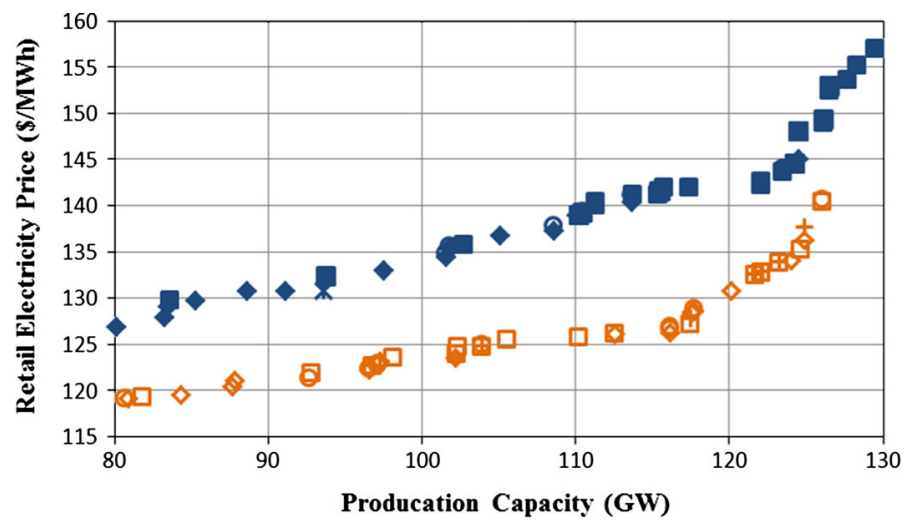

\begin{tabular}{llll}
\hline Scenarios: & Government & OBA-Excluding Coal & \\
\hline Technologies: & Coal & Existing Gas \& Oil & Existing RE \\
& Nuclear & New Nat Gas & + \\
& & New RE \\
\hline
\end{tabular}

Fig. 3 The variable cost schedule under cap and trade when revenues are distributed to government compared with the reordered schedule with targeted output-based allocation excluding coal (upper Midwest, 2020)

ment and investment by 2020 are evident in different available capacity, and the lower variable cost under targeted updated allocation is evident over the entire range displayed. The equilibrium that results under these scenarios is reported in Sect. 4.

\section{Results}

We solve the model over a 22-year horizon from 2013 to 2035, within which 2020-2035 is the compliance period for policy scenarios. Here we report results only for 2020, but the results reflect investment and compliance decisions that are forward looking to 2035. Results 
for 2025 appear in the "Appendix". First we examine results in the upper Midwest and then we report results at the national level. The primary comparison is between the outcomes of various policy choices in the upper Midwest when the rest of the nation uses a tradable performance standard. In particular we are interested in the emissions changes that occur if the upper Midwest moves away from an emissions rate standard to emissions cap-and-trade. Burtraw et al. (2014) explore similar comparisons to illustrate the possibility for leakage. We do not consider the benefits of reductions of any of the pollutants that we discuss, but it is noteworthy that EPA expects changes in emissions of conventional pollutants, especially $\mathrm{SO}_{2}$, to have economic benefits that are at least as great as those from reductions in $\mathrm{CO}_{2}$ (EPA 2014).

\subsection{Upper Midwest}

We find that the CPP, if implemented through six regional tradable performance standards, would reduce electricity sector $\mathrm{CO}_{2}$ emissions in the upper Midwest region to 484 million short tons, a reduction of $10 \%$ from Baseline levels for 2020 in that region (Table 2). The $\mathrm{CO}_{2}$ emissions in the upper Midwest are held constant at the level observed in the tradable emissions rate performance standard (TPS) scenario across all the other policy scenarios. This includes the scenario parenthetically labeled OBA-All Covered in the tables, which by construction is equal to the TPS scenario. OBA-All Covered sources uses emissions allocation to exact mimic the production incentives of the TPS scenario and consequently it achieves the same outcome. The other cap and trade scenarios implement different production incentives and the $\mathrm{CO}_{2}$ outcomes vary at the national level, but are consistent within the upper Midwest region.

Across the scenarios the generation technology mix used in the region varies, even as the $\mathrm{CO}_{2}$ emissions are consistent. The different choice of technology leads to changes in emissions of $\mathrm{SO}_{2}$ and $\mathrm{NO}_{x}$. These co-pollutants tend to be most closely associated with changes in coal-fired generation in the region.

In the Baseline, the upper Midwest exports about $4 \%$ of the power it generates. Under TPS, the export share doubles to $8 \%$ and total generation increases slightly. This reflects the region's relatively high emissions rate standard and opportunity for renewable investment. When cap and trade is introduced and auction revenues accrue to the government (the Government scenario), the export share falls to $2 \%$ (demonstrating the possibility for leakage). The Government scenario leads to higher electricity prices and reduced consumption and generation. It leads to virtually no generation from new gas units and thus makes room for more generation from coal, with an associated increase in emissions of $\mathrm{SO}_{2}$ and $\mathrm{NO}_{x}$.

When revenues are directed to local distribution companies (the LDC scenario), they reduce retail electricity prices compared with the Government scenario and serve as an incentive for consumption. The electricity prices that are achieved are similar to the TPS scenario. The key difference between the LDC and TPS scenarios is that wholesale prices are elevated under LDC because generators in the region face an allowance cost but receive no direct production incentive. Elevated wholesale prices in the upper Midwest region provide an increased incentive for neighboring states to sell power into the upper Midwest; they receive the elevated wholesale price, but do not face the regional allowance burden. The result is that net exports are lowest of all under the LDC scenario, yielding the greatest amount of leakage. In contrast, under the TPS scenario the production incentive yields a lower wholesale power price in the region and a relatively lower incentive for power imports and greater incentive for exports. 


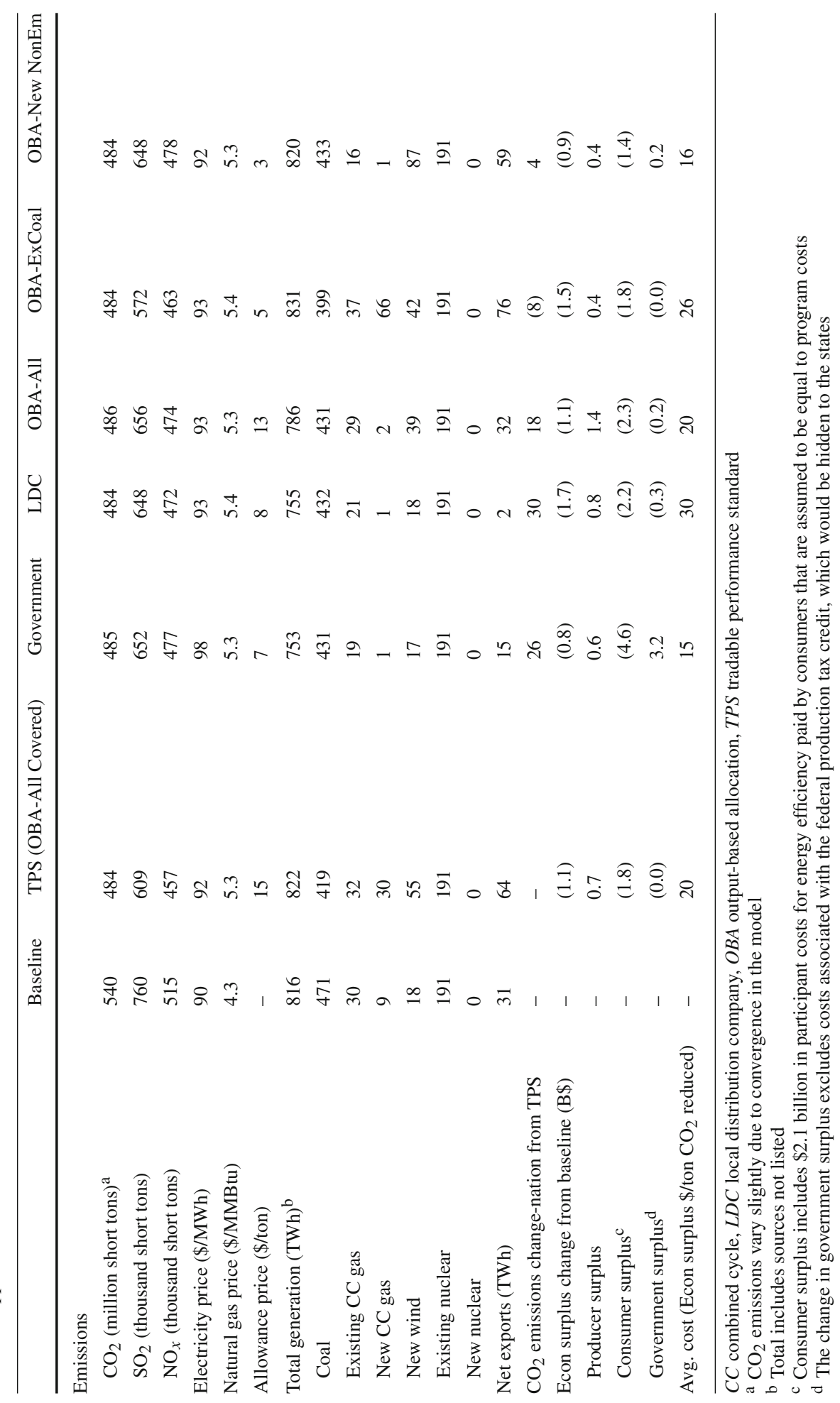


The net incentives under OBA-All are more similar to those in the LDC scenario than any other. Under output-based allocation, as under TPS, the production incentive is reflected in reduced wholesale power prices compared to Government or LDC allocation. Under LDC allocation, consumers receive an incentive that increases demand and wholesale power prices. Generators are indifferent to receiving payments through a production incentive or via wholesale market prices, rendering them roughly indifferent to output-based or LDC allocation. A difference emerges because under OBA-All, all generators within the region receive a production incentive but generators outside the region do not, giving them a relative advantage in other markets. In contrast, under LDC allocation all consumption in the region is subsidized without regard to where generation occurs. The result is that OBA-All yields fewer imports (more net exports) and less leakage than under LDC.

Compared with TPS, OBA-All generates leakage by broadening the production incentive to technologies that are not responsive (existing hydro and nuclear), thereby reducing the incentive for generators that are responsive (fossil units and new wind).

Allocation to the sources covered by TPS, but excluding coal, (OBA-ExCoal) concentrates the production incentive on relatively low carbon intensity generators. This leads to substantial growth in production from new and existing natural gas units-more than double for new investments-compared to the TPS scenario. That expanded generation is directed in part to increased power exports from the upper Midwest, and a reduction in generation and emissions outside the upper Midwest region, resulting in negative leakage. It also drives a decline in production from coal generators inside the region, since they do not receive a production incentive, leading to the lowest $\mathrm{SO}_{2}$ emissions among all of the scenarios.

Under output-based allocation directed exclusively to new nonemitting sources (OBANew NonEm), non-emitters receive a production incentive and emitters do not, reducing the scarcity of emissions allowances. The price of allowances falls to $\$ 3$ per ton, reducing the production incentive that is available for distribution to the eligible sources. The coal fleet benefits most from reduced allowance prices, and coal generation grows relative to TPS. New wind also expands, while gas generation is lower than in any other scenario. This phenomenon-the lowest-emitting sources enable the highest-emitting sources to coexisthas been observed in other contexts (Böhringer et al. 2010). Net exports under OBA-New NonEm are similar to those under TPS, showing only slight leakage.

The change in economic surplus is measured as the sum of changes in producer and consumer surplus and government revenue. ${ }^{18}$ We report the change from Baseline. The change in consumer surplus stems from changes in the electricity price, which includes the system benefits charge for programmatic expenditures on EE as well as other changes in equilibrium, and it includes the participant contribution to EE measures, which is assumed to equal the programmatic contribution (about $\$ 2$ billion). Although the costs of EE expenditures are recorded in the current year, the benefits accrue over several years into the future. Hence, the net costs appear greatest in the first year of CPP implementation. By 2025, the consumer surplus associated with the program turns positive in all scenarios, reflecting the benefits of accumulated investments in EE (Table 4 in "Appendix").

The greatest loss in consumer surplus occurs under the Government scenario because of the increase in electricity price, but this is offset by the relative gain in government surplus.

\footnotetext{
18 Producer surplus is the sum of revenues minus costs, including annualized capital expenditures. Consumer surplus is a partial equilibrium measure that holds the demand function fixed at Baseline levels and uses price changes between the Baseline and policy scenarios. Quantity changes account for the programmatic energy efficiency expenditures that are proportinal to consumption level across the scenarios. Government revenues include the federal renewable energy production and investment tax credits, as well as conventional taxes on retail electricity.
} 
Changes in government expenses due to the federal production tax credit for renewables affect the government surplus at the national level under all scenarios, but this cost is excluded in the accounting of government within the region because the cost is hidden from the states. The change in producer surplus from the Baseline is positive in each scenario, reflecting in part the increase in net exports in several scenarios compared with the Baseline. This change occurs entirely in Illinois, the only state in the upper Midwest with market-based electricity pricing. By design in the model, states with cost-of-service regulation have zero producer surplus.

The electricity sector (consumers and producers) is best off when the value of emissions allowances stays in the sector, but the total change in economic surplus, including the change in government surplus in the region, is lowest when there is no consumption or production incentive, as under the Government scenario. This is consistent with previous findings (Burtraw et al. 2001; Böhringer and Lange 2005), although in this partial equilibrium context we do not account for the opportunity to offset pre-existing distortionary taxes or changes in the real wage that exist in a general equilibrium context.

Finally, we report the average cost, measured as the change in economic surplus per ton of $\mathrm{CO}_{2}$ reduced in the region. These values range from $\$ 15$ per ton under the Government scenario to $\$ 30$ per ton under LDC allocation. As noted, a substantial portion of this cost is attributable to the program and participant shares of investment in EE, and the benefits of these investments are expected to accrue for years into the future. Under these assumptions, by 2025 the costs per ton in the upper Midwest tend to be negative (Table 4 in "Appendix").

\subsection{Nation}

We find that the CPP, if implemented through six regional tradable performance standards, would reduce electricity sector $\mathrm{CO}_{2}$ emissions in the United States in 2020 by 491 million short tons, or $23 \%$ from the level forecast in the Baseline (Table 3). Under the other scenarios, emissions in the upper Midwest are held constant under an emissions cap but vary in other regions and for the nation.

National $\mathrm{CO}_{2}$ emissions under the policy scenarios are ordered exactly opposite net exports from the upper Midwest. Leakage is greatest (net exports are smallest) under the LDC allocation and least under the scenario that excludes coal generators from an allocation (OBA-ExCoal). National $\mathrm{CO}_{2}$ emissions are likewise greatest under LDC and least under OBA-ExCoal. LDC leads to a $2 \%$ increase in national emissions relative to TPS, while OBA-ExCoal leads to $0.5 \%$ decrease.

National $\mathrm{SO}_{2}$ and $\mathrm{NO}_{x}$ emissions are positively correlated with $\mathrm{CO}_{2}$ emissions, but the ordering is not exact. We find a range of $\mathrm{SO}_{2}$ outcomes that vary from $4 \%$ below TPS (under OBA-ExCoal) to $4 \%$ above (under OBA-All). $\mathrm{NO}_{x}$ emissions rise under every deviation from TPS, by virtually zero under OBA-ExCoal up to a $3 \%$ increase under Government retention of allowance value.

Comparison of economic surplus at the national level across scenarios is ambiguous because emissions outcomes are not equal. A noteworthy factor at the national level is the change in the natural gas price as a consequence of changes in the use of gas for electricity generation. The change in the gas price indicates that changes in economic costs will accrue outside the electricity sector, but they are not reported explicitly in our results.

The average change in national economic surplus per ton of $\mathrm{CO}_{2}$ reduced is least $(\$ 41)$ under Government allocation and greatest (\$45) under the LDC scenario. These are also the least and greatest cost scenarios in the upper Midwest. By 2025, after the benefits of investments in $\mathrm{EE}$ begin to accrue, the costs fall to $\$ 4$ per ton under the Government scenario 


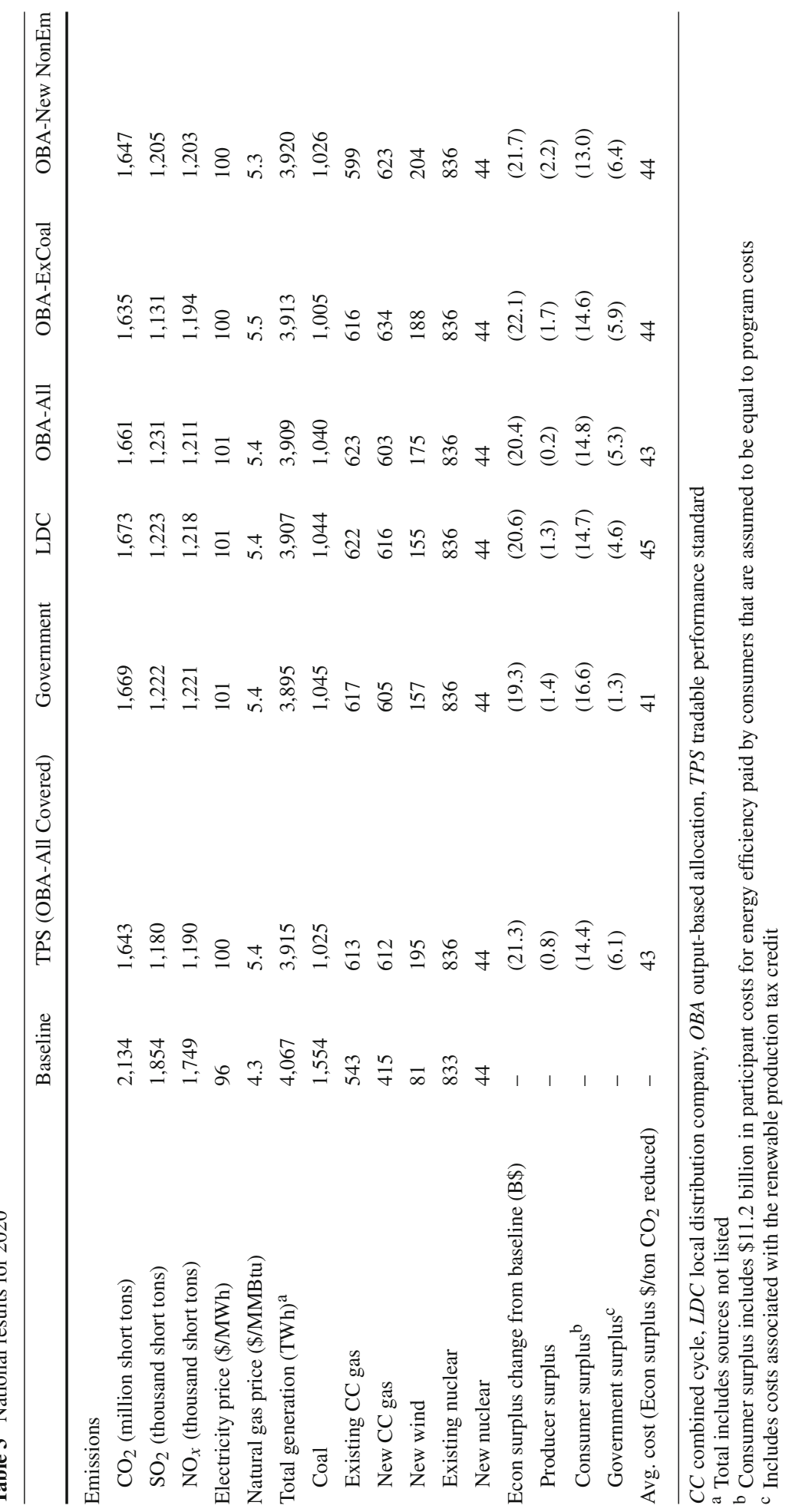


and range up to $\$ 10$ per ton under OBA-ExCoal (Table 5 in "Appendix"). Again, these are also the least and greatest cost scenarios in the upper Midwest.

\subsection{Summary}

In the upper Midwest, $\mathrm{CO}_{2}$ emissions are held stable across the scenarios but there are changes in emissions of $\mathrm{SO}_{2}$ and $\mathrm{NO}_{x}$. Figure 4 illustrates that compared with the TPS scenario, these emissions increase under all the scenarios except OBA-ExCoal, which gives a production incentive to covered sources excluding coal. In this and subsequent figures in this section, lower values would generally be considered desirable. The change in emissions will be an important consideration for states because of other obligations to achieve National Ambient Air Quality Standards, and because a substantial portion of benefits is associated with reducing these emissions.

Figure 5 illustrates that electricity prices vary little, except in the case of the Government scenario, when they are highest. However, the average cost per ton incurred within the region is lowest under the Government scenario.

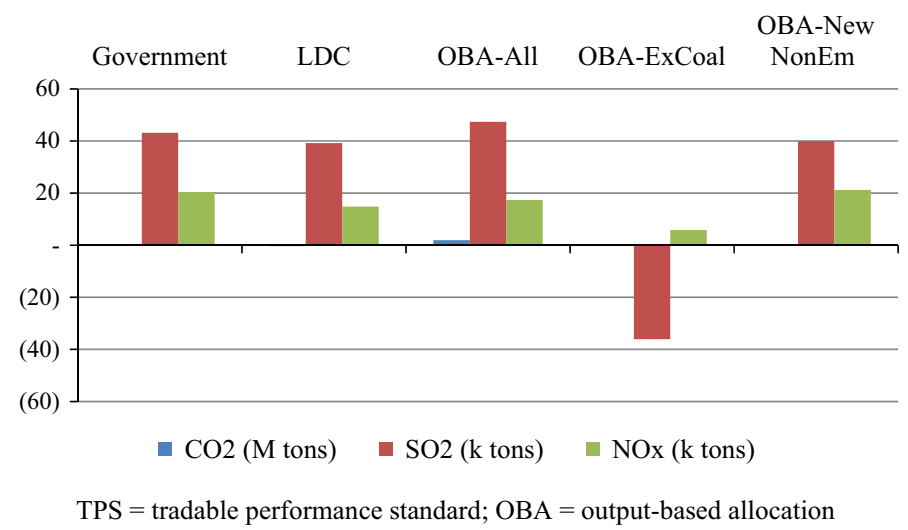

Fig. 4 Emissions changes from TPS in upper Midwest (2020)

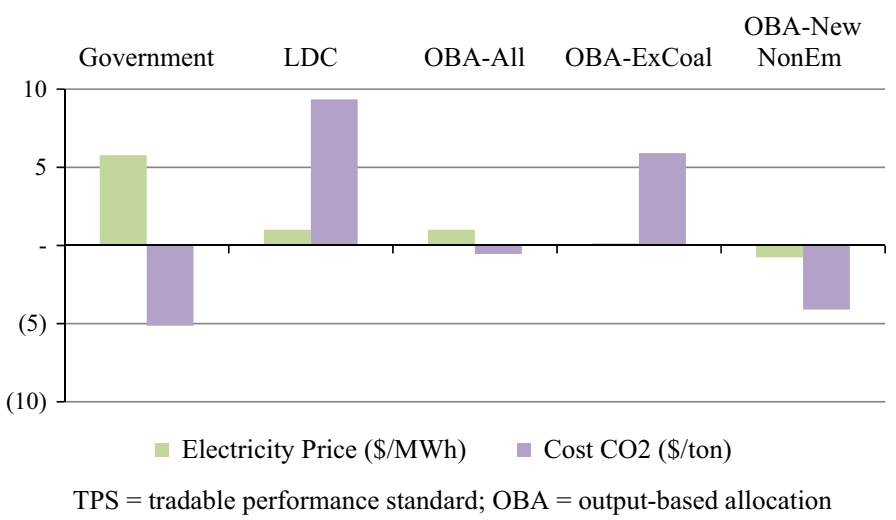

Fig. 5 Price and cost changes from TPS in upper Midwest (2020) 


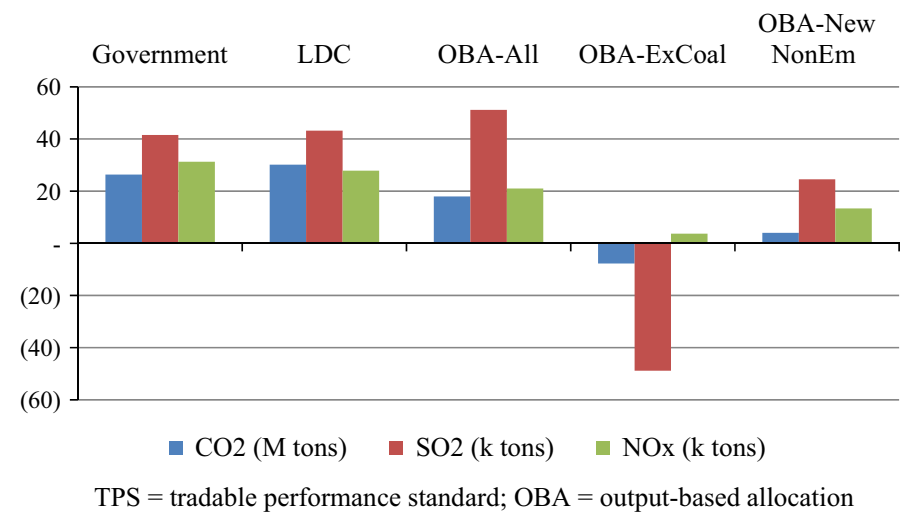

Fig. 6 Emissions changes from TPS for nation (2020)

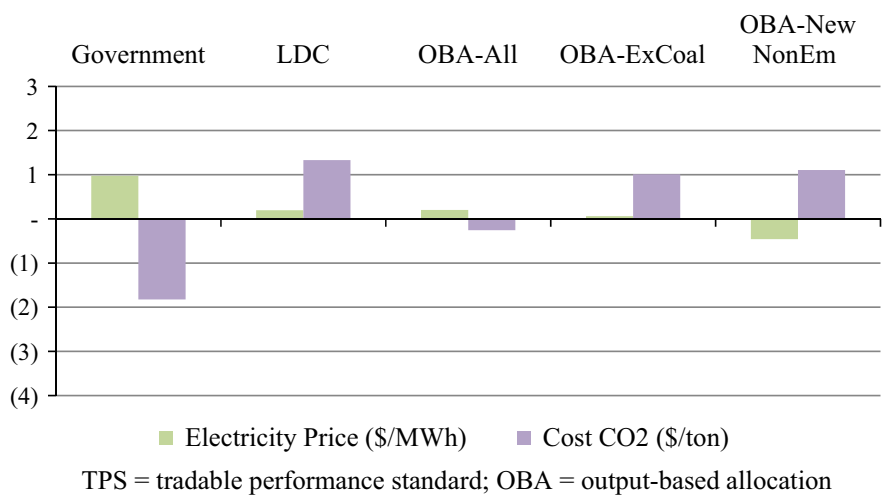

Fig. 7 Price and cost changes from TPS for nation (2020)

Figure 6 illustrates that at the national level, $\mathrm{CO}_{2}$ emissions increase under the Government, LDC, and OBA-All scenarios compared with TPS, but they decrease or are nearly unchanged under the two targeted allocation scenarios, indicating negative leakage in the case of OBA-ExCoal. Emissions of other pollutants increase in the other scenarios relative to TPS, but they are reduced (or virtually unchanged) when coal is excluded from receiving the production incentive. Figure 7 illustrates that the change in the national average electricity price is virtually zero across all the scenarios except Government, as was observed in the upper Midwest. The average cost per ton reduced is similar at the national level across the scenarios, but the lowest value is observed in the Government scenario, again, as in the upper Midwest.

\section{Conclusion}

The landscape for international climate policy has moved away from a coordinated effort to one in which nations are encouraged to make nationally determined, independent contributions. This change is reflected in the United States, where climate policy has emerged under the Clean Air Act in the form of the Clean Power Plan, which gives states primary responsibility for planning, implementation, and enforcement. Compared with the 
international setting, the situation in the US power sector has the advantage that a performance goal for each state is identified at a higher level of government. However, that goal is an intensity standard covering a crafted set of generation resources, including energy efficiency, each of which has effects on the power system across state lines. State decisions may have a substantial effect on the aggregate costs and emissions outcomes that are achieved.

States may comply using an emissions rate standard, with cap and trade or with other combinations of state policy measures. Unintended outcomes are possible, including strategic behavior by some states to capture market share through the design of their state policies. The potential interaction among states with rate-based intensity standards and those with massbased emissions caps could result in economic and emissions leakage and increase overall emissions and degradation of air quality compared with national uniform implementation of either the intensity standard or cap and trade. Unfortunately, stronger federal direction about program implementation by states appears to be difficult politically and legally, just as such direction from above is difficult at the international level. The coordination problem among US states is substantial.

We use a detailed model of the US electricity system to show that states can design their cap-and-trade policies to avoid leakage, or even to achieve negative leakage, through the allocation of emissions allowances. A tradable emissions rate standard provides a production incentive at the emissions rate standard. Updating output-based allocation can mimic this production incentive by allocating allowances according to the same formula and thereby evade the potential negative interaction of some states' emissions rate standards with other states' cap-and-trade policies. From that starting point, we show that targeting allocation to provide a production incentive to selected technologies can result in negative leakage and a reduction in total emissions. This approach has efficiency consequences. For example allocation to all sources except coal would lower $\mathrm{CO}_{2}$ and $\mathrm{SO}_{2}$ emissions nationally, but it would raise costs in the cap-and-trade region and for the nation compared to a rate-based approach in all regions. Targeted allocation only to new nonemitting sources is almost emissions neutral. It would lower the costs in the cap-and-trade region, but still raise costs for other regions and the nation. These options allow states to consider policies that can capture the administrative advantages of cap and trade without undermining the overall policy objective of reducing carbon emissions. This is a policy tool that may not have to be used to have an effect. Recognizing this policy response and the overall increase in costs from failing to coordinate, neighboring regions may choose to cooperate in using a cap-and-trade approach. We explore the policy equilibrium in ongoing research. The lessons in the United States may reflect back on the international stage, where leakage and policy interactions have been prominent in the policy dialogue.

Acknowledgments This research was supported by the Energy Foundation, RFF's Center for Energy and Climate Economics, and Mistra's INDIGO research program. Model development was supported by the Alliance for Sustainable Energy, LLC, the manager and operator of the National Renewable Energy Laboratory, the US Department of Energy, and the US Environmental Protection Agency. The authors are indebted to Hang Yin and Samantha Sekar for assistance and for comments from Larry Goulder and Franz Litz. All findings and errors remain the responsibility of the authors.

Open Access This article is distributed under the terms of the Creative Commons Attribution 4.0 International License (http://creativecommons.org/licenses/by/4.0/), which permits unrestricted use, distribution, and reproduction in any medium, provided you give appropriate credit to the original author(s) and the source, provide a link to the Creative Commons license, and indicate if changes were made. 


\section{Appendix: The Haiku Electricity Market Model}

The simulation modeling uses the Haiku electricity market model, ${ }^{19}$ which is a partial equilibrium model that solves for investment in and operation of the electricity system in 22 linked ${ }^{20}$ regions of the continental United States, from 2013 to 2035. Each simulation year is represented by three seasons (spring and fall are combined) and four times of day. For each time block, demand is modeled for three customer classes (residential, industrial, and commercial) in a partial adjustment framework that captures the dynamics of the long-run demand responses to short-run price changes. Supply is represented using 53 model plants in each region, including various types of renewables, nuclear, natural gas, and coal-fired power plants. Assumed levels of power imports from Mexico and Canada are held fixed for all scenarios. Thirty-nine of the model plants in each region aggregate existing capacity according to technology and fuel source from the complete set of commercial electricity generation plants in the country. The remaining 17 model plants represent new capacity investments, again differentiated by technology and fuel source. Each model coal plant has a range of capacity at various heat rates, representing the range of average heat rates at the underlying constituent plants (Tables 4, 5).

Operation of the electricity system (generator dispatch) in the model is based on the minimization of short-run variable costs of generation, and a reserve margin is enforced based on margins used by the Energy Information Administration in the Annual Energy Outlook (AEO) for 2013 (EIA 2013). Fuel prices are benchmarked to the AEO forecasts for both level and supply elasticity. Coal is differentiated along several dimensions, including fuel quality and content and location of supply, and both coal and natural gas prices are differentiated by point of delivery. The price of biomass fuel also varies by region, depending on the mix of biomass types available and delivery costs. Coal, natural gas, and biomass are modeled with price-responsive supply curves, so the fuel prices respond to endogenous changes in demand for these fuels. Prices for nuclear fuel and oil, as well as the price of capital and labor, are held constant.

Investment in new generation capacity and the retirement of existing facilities are determined endogenously ${ }^{21}$ for an intertemporally consistent (forward-looking) equilibrium, based on the capacity-related costs of providing service in the present and into the future (going-forward costs) and the discounted value of going-forward revenue streams. Existing coal-fired facilities also have plant-specific opportunities ${ }^{22}$ to make endogenous investments to improve their efficiency. Discounting for new capacity investments is based on an assumed real cost of capital of $5 \%$. Investment and operations include pollution control decisions to comply with regulatory constraints for $\mathrm{SO}_{2}, \mathrm{NO}_{x}$, mercury, hydrochloric acid, and particulate matter, including equilibria in emissions allowance markets where relevant. All currently available generation technologies identified in AEO are represented in the model, as are inte-

\footnotetext{
19 Haiku is comparable in sectoral and geographic coverage to the Integrated Planning Model (IPM, owned by ICF consulting and the model of record for EPA), ReEDS (maintained at the National Renewable Energy Laboratory), and the Electricity Market Module of the National Energy Modeling System (NEMS, maintained by the Energy Information Agency). Haiku, IPM, and ReEDS model the electricity sector and partially model factor markets, like fuel, for the continental United States. NEMS also links its electricity sector model to the entire economy and models all fuel markets. For more information about the Haiku electricity market model, see Paul et al. (2009).

20 Interregional transmission capability is drawn from EIA (2013).

21 Investment (in both generation capacity and pollution controls) and retirement are determined according to cost-minimization.

22 Linn et al. (2014).
} 


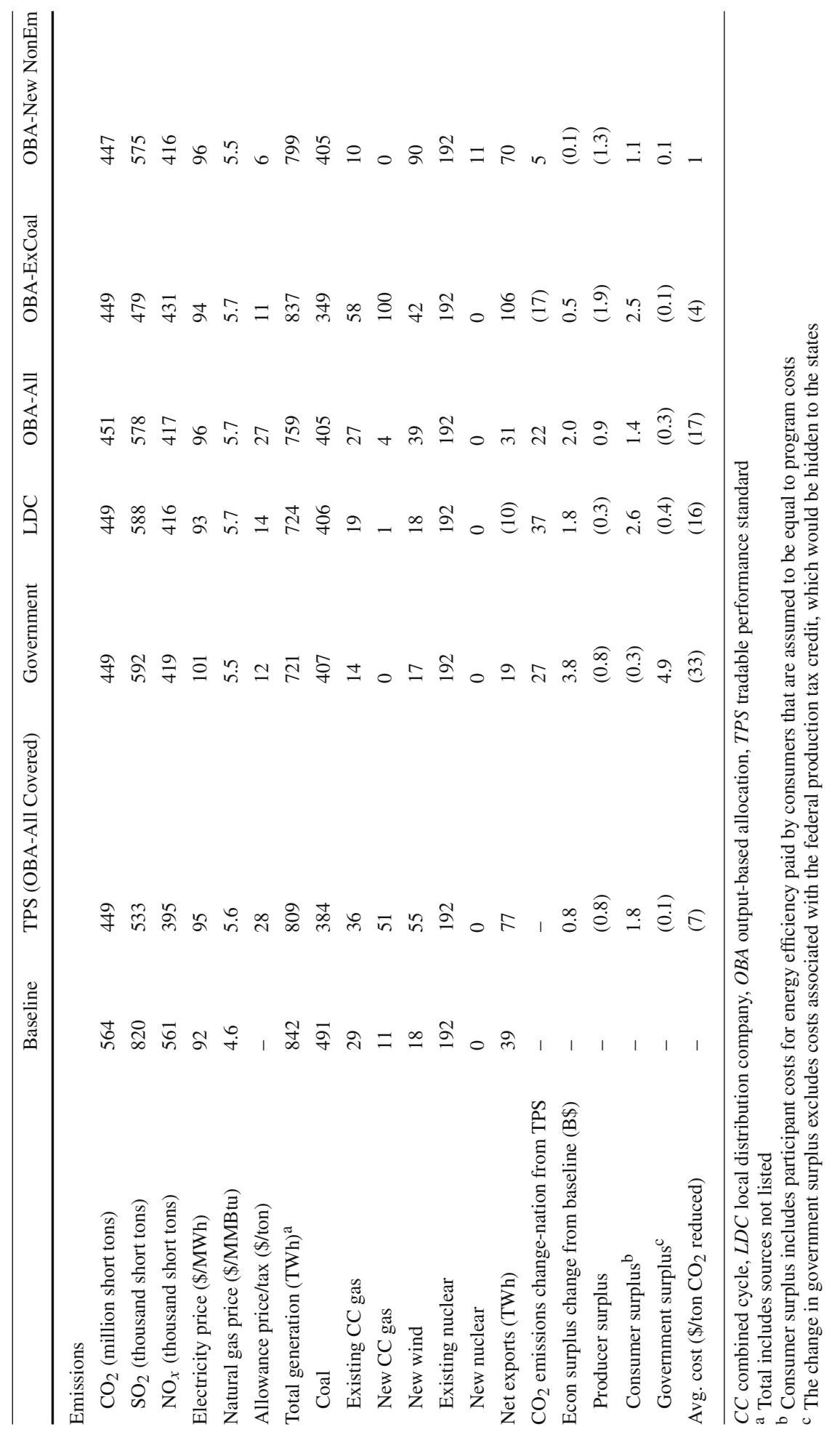




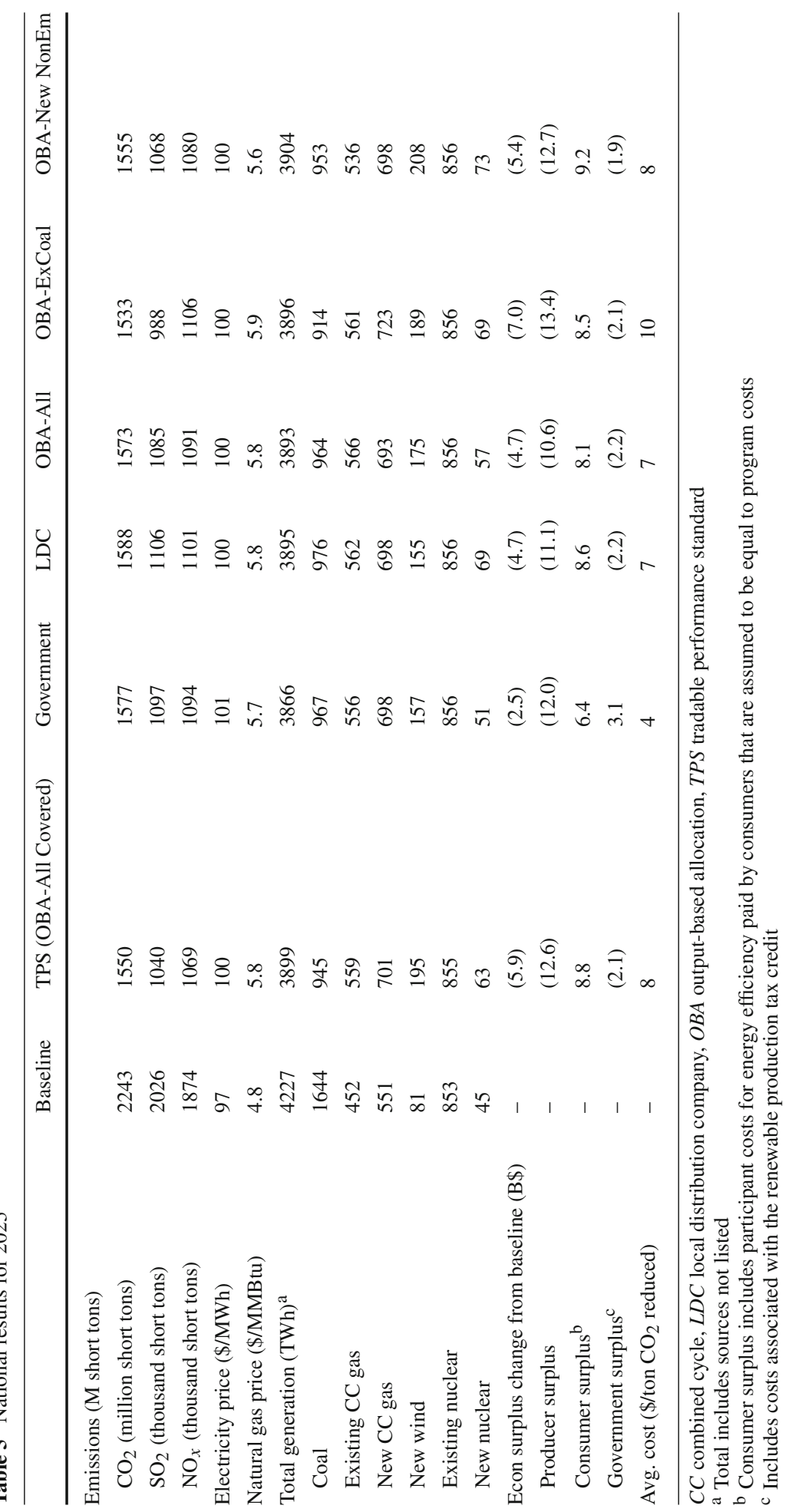


grated gasification combined-cycle coal plants and natural gas combined-cycle plants, both with carbon capture and storage. Ultra-supercritical pulverized coal plants and carbon capture and storage retrofits at existing facilities are not available in the model. The model does not capture the role of complex fuel contracts in decisions to retire a plant. Although short-term contracts are common in coal markets, long-term contacts could play a role in retirement decisions. If long-term contracts incentivize some plants to remain in operation, this modeling omission likely leads to an overestimate of coal-fired retirement projections and, potentially, other new investment. Price formation is determined by cost-of-service regulation or by competition in different regions, corresponding to current regulatory practice. Electricity markets are assumed to maintain their current regulatory status throughout the modeling horizon; that is, regions that have already moved to competitive pricing continue that practice, and those that have not made that move remain regulated. ${ }^{23}$ The retail price of electricity does not vary by time of day in any region, though all customers face prices that vary from season to season.

The model requires that each region have sufficient capacity reserve to meet requirements drawn from AEO. The reserve price reflects the scarcity value of capacity and is set just high enough to retain just enough capacity to cover the required reserve margin in each time block. In competitive regions, the reserve price is paid within a capacity market framework within each time block to all units that generate electricity and to those that provide additional capacity services. We do not model separate markets for spinning reserves and capacity reserves. Instead, the fraction of reserve services provided by steam generators is constrained to be no greater than $50 \%$ of the total reserve requirement in each time block.

\section{References}

ACEEE (2014) State energy efficiency resource standards. American Council for an Energy-Efficient Economy, Washington DC

Böhringer C, Lange A (2005) On the design of optimal grandfathering schemes for emissions allowances. Eur Econ Rev 49:2041-2055

Böhringer C, Rosendahl K (2010) Green promotes the dirtiest: on the interaction between black and green quotas in energy markets. J Regul Econ 37(3):316-325

Burtraw D, Kahn D, Palmer K (2006) $\mathrm{CO}_{2}$ allowance allocation in the regional greenhouse gas initiative and the effect on electricity investors. Electr J 19(2):79-90

Burtraw D, Linn J, Palmer K, Paul A (2014) The costs and consequences of Clean Air Act regulation of $\mathrm{CO}_{2}$ from power plants. Am Econ Rev Pap Proc 104(4):557-562

Burtraw D, Palmer K, Bharvirkar R, Paul A (2001) The effect of allowance allocation on the cost of carbon emission trading. Resources for the Future, Washington DC

Burtraw D, Sekar S (2014b) Two world views on carbon revenues. J Environ Stud Sci 4(1):110-120

Burtraw D, Woerman M, Paul A (2012) Retail electricity price savings from compliance flexibility in GHG standards for stationary sources. Energy Policy 42:67-77

Bushnell J, Chen Y (2012) Allocation and leakage in regional cap-and-trade markets for $\mathrm{CO}_{2}$. Resour Energy Econ 34:647-668

Bushnell J, Holland SP, Hughes J, Knittel CR (2014) Strategic policy choice in state-level regulation: the EPA's Clean Power Plan. University of California Energy Institute working paper 255

EIA (2013) Annual energy outlook 2013. Energy Information Administration, Washington DC

EPA (2014) Regulatory impact analysis for the proposed carbon pollution guidelines for existing power plants and emission standards for modified and reconstructed power plants. EPA -542/R-14-002

Fischer C (2003) Combining rate-based and cap-and-trade emissions policies. Clim Policy 3(Supplement 2):S89-S103

23 There is currently little momentum in any part of the country for further electricity market regulatory restructuring. Some of the regions that have already implemented competitive markets are considering reregulating parts of the industry. 
Fischer C, Newell R, Proeonas L (2013) Environmental and technology policy options in the electricity sector: interactions and outcomes. Resources for the Future DP 13-20

Fowlie M, Goulder L, Kotchen M, Borenstein S, Bushnell J, Davis L, Greenstone M, Kolstad C, Knittel C, Stavins RN, Wara M, Wolak F, Wolfram C (2014) An economic perspective on the EPA's Clean Power Plan. Science 346(6211):815-816

Harstad B, Eskeland GS (2010) Trading for the futuer: signaling in permit markets. J Public Econ 94:749-760

Holland SP (2012) Emissions taxes versus intensity standards: second-best environmental policies with incomplete regulation. J Environ Econ Manag 63:375-387

Keohane RO, Victor DG (2013) The transnational politics of energy. Daedalus 142(1):97-109

Koch N, Fuss S, Grosjean G, Edenhofer O (2014) Causes of the EU ETS price drop: recession, CDM, renewable policies or a bit of everything? - new evidence. Energy Policy 73:676-685

Linn J, Mastrangelo E, Burtraw D (2014) Regulating greenhouse gases from coal power plants under the Clean Air Act. J Assoc Environ Resour Econ 1(1):97-134

Marschinski R (2008) Efficiency of emissions trading between systems with absolute and intensity targets EAERE 2008 annual conference Gothenburg. Sweden, Potsdam Institute for Climate Impact Research

NCSU (2013) Database of state incentives for renewables and efficiency. http://www.dsireusa.org/ summarytables/rrpre.cfm. Accessed 22 Jan 2015)

Paul A, Burtraw D, Palmer K (2009) Haiku documentation: RFF's electricity market model version 2.0. Resources for the Future, Washington, DC

Rosendahl KE, Storreøsten HB (2011) Emissions trading with updated allocation: effects on entry/exit and distribution. Environ Resour Econ 49:243-261 